\title{
Bite force, cranial morphometrics and size in the fishing bat Myotis vivesi (Chiroptera: Vespertilionidae)
}

Sandra M. Ospina-Garcés ${ }^{1,2}$, Efraín De Luna ${ }^{3}$,

L. Gerardo Herrera M. ${ }^{4}$ (https://orcid.org/0000-0001-9348-5040), Joaquín Arroyo-Cabrales ${ }^{5}$, \& José Juan Flores-Martínez ${ }^{6}$

1. Posgrado en Ciencias Biológicas, Instituto de Biología, Universidad Nacional Autónoma de México, Apartado Postal 70-153, 04510 México, Distrito Federal; ospinagarcess@gmail.com https://orcid.org/0000-0002-0950-4390

2. Instituto de Ecología, A.C. Carretera Antigua a Coatepec 351, El Haya, Xalapa, 91070, México, ospinagarcess@gmail.com; https://orcid.org/0000-0002-0950-4390

3. Instituto de Ecología A.C. Biodiversidad y Sistemática, Xalapa, Veracruz, 91070; efrain.deluna@inecol.mx, https:// orcid.org/0000-0002-6198-3501

4. Estación de Biología de Chamela, Instituto de Biología, Universidad Nacional Autónoma de México, Apartado Postal 21, San Patricio, Jalisco, 48980, México; gherrera@ib.unam.mx

5. Laboratorio de Arqueozoología, ‘M. en C. Ticul Álvarez Solórzano’ INAH, Moneda \# 16 Col. Centro, 06060 México, Distrito Federal; arromatu5@yahoo.com.mx

6. Laboratorio de Sistemas de Información Geográfica, Departamento de Zoología. Instituto de Biología, Universidad Nacional Autónoma de México, Circuito Exterior, Edificio Nuevo, Módulo C, Apartado Postal 70-153, 04510 México, Distrito Federal; jj@ib.unam.mx

* Correspondence

Received 06-IV-2018. C Corrected 31-VII-2018. Accepted 18-IX-2018.

\begin{abstract}
Fish-eating in bats evolved independently in Myotis vivesi (Vespertillionidae) and Noctilio leporinus (Noctilionidae). We compared cranial morphological characters and bite force between these species to test the existence of evolutionary parallelism in piscivory. We collected cranial distances of $M$. vivesi, two related insectivorous bats ( $M$. velifer and $M$. keaysi), two facultatively piscivorous bats ( $M$. daubentonii and $M$. capaccinii), and N. leporinus. We analyzed morphometric data applying multivariate methods to test for differences among the six species. We also measured bite force in $M$. vivesi and evaluated if this value was well predicted by its cranial size. Both piscivorous species were morphologically different from the facultatively piscivorous and insectivorous species, and skull size had a significant contribution to this difference. However, we did not find morphological and functional similarities that could be interpreted as parallelisms between $M$. vivesi and $N$. leporinus. These two piscivorous species differed significantly in cranial measurements and in bite force. Bite force measured for $M$. vivesi was well predicted by skull size. Piscivory in $M$. vivesi might be associated to the existence of a vertically displaced temporal muscle and an increase in gape angle that allows a moderate bite force to process food.
\end{abstract}

Key words: bite force; cranial morphology; Myotis; Noctilio; piscivory; size; gape angle.

Ospina-Garcés, S.M., De Luna, E., Herrera M., L.G., Arroyo-Cabrales, J., \& Flores-Martínez, J.J. (2018). Bite force, cranial morphometrics and size in the fishing bat Myotis vivesi (Chiroptera: Vespertilionidae). Revista de Biología Tropical, 66(4), 1614-1628.

The relationship between the structure of the masticatory apparatus and diet has long been investigated in bats (Freeman, 1981; 1984; Van Cakenberghe, Herrel, \& Aguirre,
2002, Swartz, Freeman, \& Stockwell, 2003; Nogueira, Monteiro, Peracchi, \& De Araújo, 2005; Dumont, Herrel, Medellin, Vargas-Contreras, \& Santana, 2009; Nogueira, Peracchi, 
\& Monteiro, 2009). Morphological differences in cranial size are related to differences in diet and have consequences in the performance of the masticatory muscles. For example, volume, length and position of the temporal and masseter muscles vary among bat species from different dietary groups (Dumont, 1999; Freeman, 1981; 1984, Nogueira et al., 2005, Swartz et al., 2003; Van Cakenberghe et al., 2002; Dumont et al., 2009). Such morphological variation could be related to size and hardness of food items because these two features affect the performance of the masticatory muscles (Dumont, 1999; Nogueira et al., 2005; Ghazali \& Dzeverin, 2013).

Masticatory performance in bats has been estimated analyzing bite force in relation to body size and masticatory muscle morphology. Body size and bite force are highly correlated, as well as bite force and mass and length of fibers of the masticatory muscle (Aguirre, Herrel, Van Damme, \& Matthysen, 2002; 2003; Herrel, De Smet, Aguirre, \& Aerts, 2008). Cranial size, muscle masses and the fiber length of the temporal muscle are the best predictors of bite force: species with a larger cranium, a larger temporal muscle mass and shorter temporal fiber lengths bite harder (Dumont \& Herrel, 2003). In general terms, the cranial muscular system is a good predictor of bite force (Dumont \& Herrel, 2003; Dumont et al., 2009).

Cranial traits related the performance of masticatory muscles suggest parallelisms among some bat species with the same diet. For example, insectivorous bats have narrow and elongated faces, and their zygomatic breadth is about $55-70 \%$ of the condylocanine length. In contrast, bat species that feed on small vertebrates (e.g., Noctilio leporinus, Cheiromeles torquatus, Scotophilus gigas and Saccolaimus peli) have wide and short faces, with a zygomatic breadth about $70-80 \%$ of the condylocanine length (Freeman, 1981). Cranial size and the change to vertical orientation of the temporal muscle might allow wider gapes facilitating prey processing of vertebrate-eating bats (Emerson \& Radinsky, 1980; Van Cakenberghe et al., 2002). Other cranial traits have been associated with carnivory, not only in bats but also in saber-tooth cats (Emerson \& Radinsky, 1980). A laterally-flaring angular processes, a low coronoid process, a vertically oriented temporal fossa, and a high origin/insertion ratio of the temporal muscle suggest wide gapes and strong bites in carnivorous mammals (Emerson \& Radinsky, 1980; Freeman, 1988). The piscivorous bat $N$. leporinus (Linnaeus, 1758) presents these features (Freeman, 1981; Herring \& Herring, 1974).

Piscivory in bats appeared in parallel in $N$. leporinus (Noctilionidae) and some species in the genus Myotis (Vespertilionidae). M. vivesi (Menegaux, 1901) is the only truly piscivorous species (Blood \& Clark, 1998), whereas seven other species are insectivores that occasionally feed on fish (M. ricketti, $M$. daubentonii, $M$. capaccinii, M. adversus, M. macrotarsus, $M$. albescens and M. stalkeri; Aihartza, Almenar, Goiti, Salsamendi, \& Garin, 2008; Flannery, 1995; Law \& Urquhart, 2000; Siemers, Dietz, Nill, \& Schnitzler, 2001; Whitaker \& Findley, 1980). These eight species were initially grouped in the subgenus Leuconoe with other entomophagus Myotis, due to similar external characteristics (Findley, 1972). This subgenus has not been supported by molecular techniques and is treated at present not as taxon but as an ecomorph (Ruedi \& Mayer, 2001). Typically, Leuconoe bats prey insects near the water surface and this can possibly make easier a transition to piscivory in large-sized Leuconoe. Additionally, external morphological traits are associated with the presence of fish in their diets including laterally compressed and large claws to catch prey on the water surface (Freeman, 1981; Norberg \& Rayner, 1987; LewisOritt, Van Den Bussche, \& Baker, 2001). However, a phylogenetic analysis showed that the facultatively piscivorous and piscivorous Myotis species are not a monophyletic group (Ruedi \& Mayer, 2001; Stadelmann, Herrera, Arroyo-Cabrales, Flores-Martinez, May, Ruedi, 2004). Members of the genus Myotis represent an excellent model to examine changes in the masticatory apparatus morphology 
associated to the evolution of piscivory from insectivorous ancestors (Lewis-Oritt et al., 2001). Geometric morphometric analyses performed recently in piscivorous Myotis species describe morphological changes in mandibular masticatory process position related to gape capacity and diet, and a significant effect of size in skull shape variation (Ospina-Garcés, De Luna, Gerardo-Herrera, \& Flores-Martínez, 2016). In the present study we explored if there are morphological differences in the masticatory apparatus of $M$. vivesi with respect to their facultatively piscivorous (M. capaccinii and $M$. daubentonii) and insectivorous relatives (M. keaysi and M.velifer), and the effect of skull size in this variation. We included $N$. leporinus in the comparison to evaluate if there are parallel trends of variation in the masticatory apparatus of $M$. vivesi. In addition, we compared masticatory performance of $M$. vivesi measured as bite force in relation to skull size with data previously reported for insectivorous and facultatively piscivorous Myotis, $N$. leporinus and unrelated insectivorous species (Aguirre et al., 2002; Herrel et al., 2008).

We addressed the following questions: 1) does cranial morphology and performance of $M$. vivesi differ compared to their facultatively piscivorous or insectivorous relatives and are cranial morphotypes in $M$. vivesi similar enough to be interpreted as parallelism in the non-related piscivorous $N$. leporinus?, and 2) are the morphological and functional differences explained by the increase of skull size in both piscivorous species? We hypothesized that cranial morphology and performance of $M$. vivesi would differ with respect to insectivorous and facultatively piscivorous Myotis, but present similarities with $N$. leporinus. We expected that the position and development of the masticatory muscles would be more different between $M$. vivesi and insectivorous Myotis than with respect to the masticatory morphology in facultatively piscivorous Myotis. We also anticipated that bite force in $M$. vivesi would be similar to that expected for its size, and that size-corrected bite force would be similar to that of $N$. leporinus.

\section{MATERIALS AND METHODS}

Study system: We examined skulls and jaws from 228 adult bat specimens of two piscivores (Myotis vivesi: 20 females, 27 males; Noctilio leporinus: 27 females, 24 males), two insectivores (M. velifer: 26 females, 27 males; M. keaysi: 31 females, 19 males) and two facultatively piscivores (M. daubentonii: 12 females, 4 males; M. capaccinii: 5 females, 6 males). Age of specimens was assessed following the criteria proposed by Pacheco \& Patterson (1992). Specimens (Appendix) belong to the National Mammal Collection (México), the Osteological Collection of the National Institute of Anthropology and History (México), the Doñana Biological Station (Spain), and the Humboldt University Natural History Museum (Germany).

Measurements: Inter-landmark distances were collected using a digital caliper (Mitutoyo CD-6" Mitutoyo U.S.A.) to the nearest $0.01 \mathrm{~mm}$ on the right side of skull and jaw. We measured nine dimensions on the skull and five on the jaw (Fig. 1) from each individual: 1. Greatest skull length (GSL), 2. Maximum zygomatic breadth (MZB), 3. Condylocanine lenght (CCL), 4. Toothrow lenght (MTR), 5. Maxillary breadth across M3 (M3B), 6. Temporal origin (Ori T), 7. Temporal insertion (ins T), 8. Postorbital constriction width (POC), 9. Masseter origin (Ori M), 10. Masseter insertion (Ins M), 11. Dentary lenght (DL), 12. Dentary depthness under the protoconid of $\mathrm{m} 2$ (DD), 13. Coronoid process height $(\mathrm{CPH}), 14$. Masseteric fosa length (MFL), 15. Elevation of condyle angle (ECA), 16. Coronoid process angle (CPA).

Specific average and standard deviation were presented in Table 1. Some of these measurements are related to the development of the masticatory muscle (Emerson \& Radinsky 1980; Freeman 1984). Other measurements are related to the size of the skull, the zygomatic breadth, and the condyle canine length. Maxillary breadth indicates the length of the skull, and the dentary depth under the protoconid of 
TABLE 1

Cranial morphological distances and angles measured in five Myotis and one Noctilio species

\begin{tabular}{ccccccc} 
& M. cappacinii & M. daubentonii & M. keaysi & M. velifer & M. vivesi & N. leporinus \\
(1) GSL & $15.33(0.21)$ & $14.80(0.32)$ & $13.01(0.31)$ & $16.33(0.34)$ & $21.44(0.41)$ & $26.72(1.44)$ \\
(2) MZB & $9.33(0.19)$ & $8.98(0.31)$ & $7.96(0.25)$ & $10.69(0.26)$ & $14.06(0.3)$ & $19.27(0.73)$ \\
(3) CCL & $13.45(0.18)$ & $12.89(0.33)$ & $11.51(0.41)$ & $14.83(0.25)$ & $19.57(0.56)$ & $23.56(0.65)$ \\
(4) MTR & $5.66(0.08)$ & $5.36(0.12)$ & $4.91(0.22)$ & $6.59(0.29)$ & $9.18(0.24)$ & $10.61(0.3)$ \\
(5) M3B & $6.07(0.12)$ & $5.79(0.16)$ & $5.16(0.2)$ & $6.88(0.15)$ & $8.88(0.22)$ & $13.02(0.38)$ \\
(6) Ori T & $8.78(0.22)$ & $8.51(0.22)$ & $7.42(0.31)$ & $9.16(0.23)$ & $11.91(0.36)$ & $20.5(1.35)$ \\
(7) Ins T & $5.79(0.14)$ & $5.42(0.31)$ & $4.94(0.22)$ & $6.09(0.29)$ & $6.99(0.22)$ & $13.91(1.28)$ \\
(8) POC & $3.79(0.09)$ & $4.13(0.13)$ & $3.31(0.13)$ & $3.99(0.12)$ & $5.56(0.15)$ & $7.3(0.27)$ \\
(9) Ori M & $3.83(0.14)$ & $3.74(0.09)$ & $3.4(0.18)$ & $4.76(0.17)$ & $5.91(0.36)$ & $7.86(0.57)$ \\
(10) Ins M & $2.23(0.75)$ & $2.08(0.08)$ & $1.81(0.09)$ & $2.50(0.12)$ & $3.03(0.14)$ & $4.9(0.5)$ \\
(11) DL & $11.22(0.319)$ & $10.63(0.27)$ & $9.61(0.3)$ & $12.92(0.25)$ & $17.08(0.4)$ & $19.42(0.71)$ \\
(12) DD & $1.13(0.10)$ & $1.08(0.05)$ & $1.04(0.07)$ & $1.46(0.1)$ & $1.74(0.08)$ & $3.14(0.36)$ \\
(13) CPH & $3.00(0.13)$ & $3.00(0.13)$ & $2.69(0.16)$ & $3.94(0.14)$ & $5.03(0.17)$ & $6.69(0.27)$ \\
(14) MFL & $2.83(0.15)$ & $2.73(0.15)$ & $2.47(0.15)$ & $3.51(0.2)$ & $4.32(0.2)$ & $7.04(0.6)$ \\
(15) ECA & $0.91(0.02)$ & $0.86(0.05)$ & $0.86(0.05)$ & $0.86(0.05)$ & $0.97(0.06)$ & $1.20(0.05)$ \\
(16) CPA & $0.99(0.06)$ & $1.02(0.06)$ & $1.06(0.04)$ & $1.09(0.04)$ & $1.15(0.06)$ & $1.26(0.04)$ \\
\hline
\end{tabular}

* Values are described as mean $( \pm \mathrm{SD})$. Abbreviations of 14 cranial measurements and two angles are ordered as in Fig. 1.

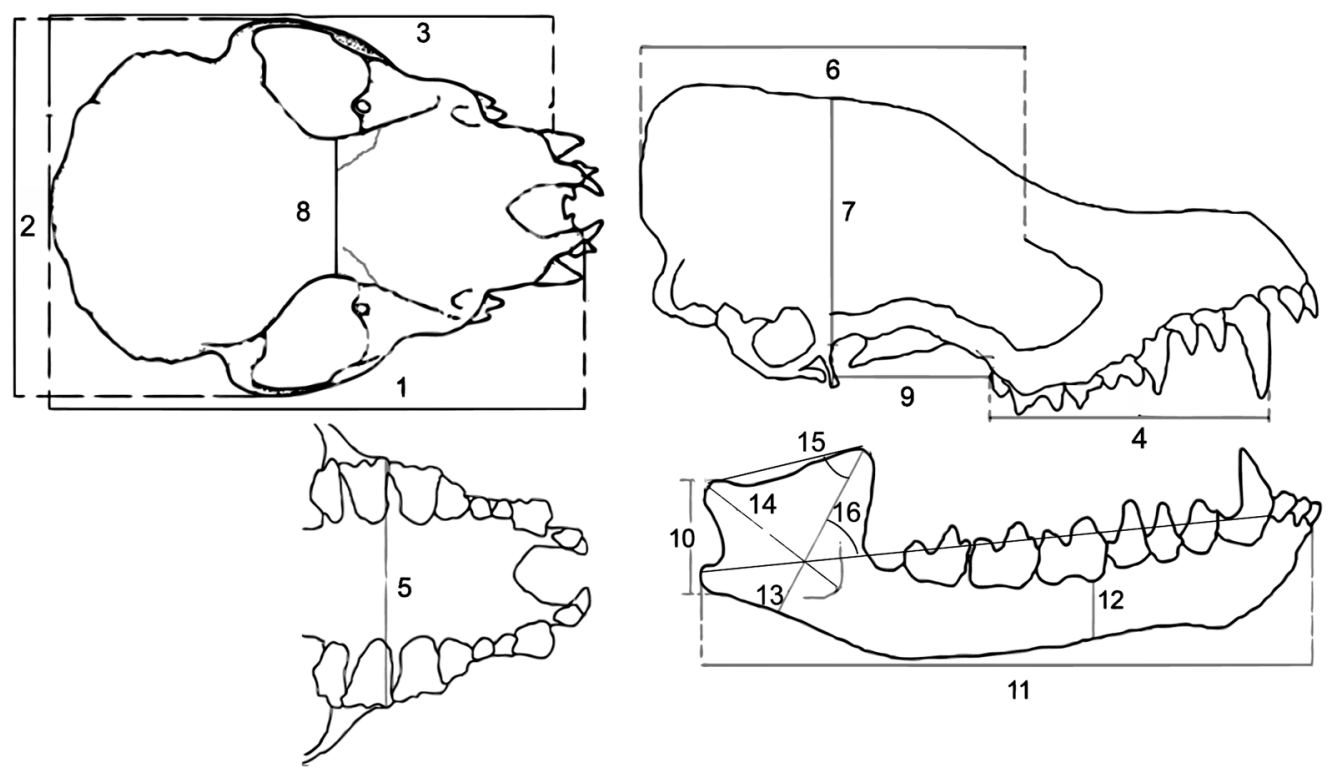

Fig. 1. Cranial measurements and angles recorded in this study. Numbers designate 14 inter-landmark distances and two angles.

$\mathrm{m} 2$ (DD) reflects the thickening of the dentary. Because there are differences in skull size among species considered, measurements were size-adjusted with a geometric mean. Distances for each individual were divided by the geometric mean of all 14 measurements from the same individual (Dumont, 2004).

Two angles were estimated on digital photographs of the right side of the mandible of each individual with the program tpsDIG2 
(Rohlf, 2005). We used the elevation of the coronoid process and the elevation of the condyle angles to infer the direction of the masseter and temporal muscles. The elevation of the coronoid process angle (CPA) was measured between the lines corresponding to the height of the coronoid process and the dentary line (Fig. 1). The elevation of the condyle angle (ECA) was measured between the lines corresponding to the coronoid process height and a line from the condyle to the coronoid process (Fig. 1). The angles estimate the height of the coronoid and condylar processes respect to the dentary and therefore the orientation of the masticatory muscles (Emerson \& Radinsky, 1980). Both angle values were transformed to radians for further statistical analyses (variables 15 and 16, Table 1).

We measured bite force using a piezo resistive force sensor (Flexiforce A 201-100, Tekscan, Inc., Boston), with a sensitivity range of $0-100$ pounds. This device consists of a plate that works like a load cell in an electrical circuit; it has a resistance that changes with the force applied in a sensible area at the end of the plate where the lowest electrical resistance corresponds to the maximum force. We obtained the resistance of the cell with an industrial multi-meter (Techmaster D-8500, Techmaster de México S.A., Tijuana) with a sensibility of $400 \mathrm{M} \Omega$. This instrument requires a pressure of at least three seconds to show any recording. The force applied is calculated by a regression using resistance values from the application of known weights.

Bite force was estimated from 15 adults of $M$. vivesi ( 3 males and 12 females; body mass: $30.85 \pm 4.8 \mathrm{~g}$, mean $\pm \mathrm{SD})$. Specimens were caught in Partida Norte Island, México $\left(28^{\circ}\right.$ $53^{\prime} 30^{\prime \prime} \mathrm{N}-113^{\circ} 02^{\prime} 25^{\prime \prime} \mathrm{W}$ ) and weighted with a PESOLA precision scale (100 g maximum capacity, MICROLINE, Switzerland). Bite force measurements were made in situ between 09:00 am and 1:00 pm. The specimens were placed in front of the sensor so that the mouth occupied the first third of the sensitive area because the plate is larger than the mouth. This procedure was performed three times for each individual and low-pressure readings were discarded. We used the lowest resistance measurements recorded that correspond to the highest bite force (Freeman \& Lemen, 2008). After the measurements, individuals were released at the capture site. Procedures followed guidelines approved by the American Society of Mammalogists (Sikes \& Gannon, 2011) and were collected under permission by the Secretaría de Medio Ambiente y Recursos Naturales (SEMARNAT).

Statistical analysis: Data for analyses consisted in fourteen variables measured on the skull and two angles (CPA: Coronoid Process angle and ECA: Elevation of Condyle angle) expressed as radians (Table 1). Statistical analyses were structured to compare six $a$ pRiori groups (six species). Data without transformation and size-adjusted variables were tested for normality within each species with the Shapiro-Wilk test. Since differences in size between sexes could hide differences between species, we evaluated sexual dimorphism. We performed a two-way analysis of variance (ANOVA) to test differences between species and sexes in the greatest skull length (GSL). Post-hoc comparisons between sexes within species were performed to identify species with significant dimorphism.

Multivariate differences in cranial morphology among six species were first examined with a Canonical Variate Analysis (CVA) based on variances of 14 measurements on skulls and jaws and the two angles. These sixteen variables were transformed to base 10 logarithms. A second CVA analysis with fifteen sizeadjusted variables, with GSL removed from the data matrix, was performed to determine the contribution of variables to discriminate groups when the size effect is reduced. Size contribution to the contrast between species with different body mass (Freeman, 1981) was examined by the comparison between resulting CVA analyses and calculating the correlation between the GLS and the scores of the first CV from the size-adjusted CVA. 
Bite force in $M$. vivesi was inferred from a linear regression between known weights of steel nuts $(\mathrm{N}=8)$, transformed in force $(\mathrm{N})$, and resistance $(\mathrm{M} \Omega)$. We measured the resistance of the different steel pieces added one at time to increase the force measured in Newtons and therefore the resistance of the sensor, and we performed the bivariate regression between force of each group of steel pieces and its resistance (Fig. 2). Resistances of maximum bites measured in the 15 individuals of $M$. vivesi were replaced in equation of this regression to obtain the bite force in Newtons. Bite force mean values previously reported for 10 insectivorous bat species, two facultatively piscivorous Myotis and the piscivorous $N$. leporinus (Aguirre et al., 2003, Freeman \& Lemen, 2010; Krüger, Clare, Greif, Siemers, Symondson, \& Sommer, 2014) were used to conduct a linear regression analysis with the estimator of skull size (GLS). We performed the Blomberg's K phylogenetic signal test on the residuals of this linear model following Revell (2010), using the super tree of bats (Jones, Purvis, Maclarnon, Bininda-Emonds, \& Simmons, 2002) with all branches scaled to 1 . We conducted this test with the library Phytools (Revell, 2012) for the statistical program R 3.3.3 (R Core Team, 2017). We examined if bite force estimated for $M$. vivesi fitted the $95 \%$ confidence interval of the regression to determine if it corresponded to the value predicted by its GLS. All multivariate analyses were performed in the program STATISTICA 10 (StatSoft Inc, 2011) using a significance level of $\alpha=0.05$.

\section{RESULTS}

Morphological variation: Among sixteen variables, only CCL and the CPA were not normally distributed within the six species of bats (W $<0.941, \mathrm{P}<0.05$ ). The sixteen variables transformed to logarithms were normally distributed $(\mathrm{W}>0.861, \mathrm{P}>0.05)$. Size-adjusted variables were normally distributed within the six species of bats $(\mathrm{W}>0.899, \mathrm{P}>0.05)$. There were significant differences in GLS among species $\left(\mathrm{F}_{5,216}=3111, \mathrm{P}<0.001\right)$, but not significant differences between sexes $\left(\mathrm{F}_{1,216}=0\right.$, $\mathrm{P}=0.803$ ) or the interaction between sexes and species $\left(\mathrm{F}_{5,216}=0.5, \mathrm{P}=0.576\right)$. The results of post-hoc comparisons showed significant

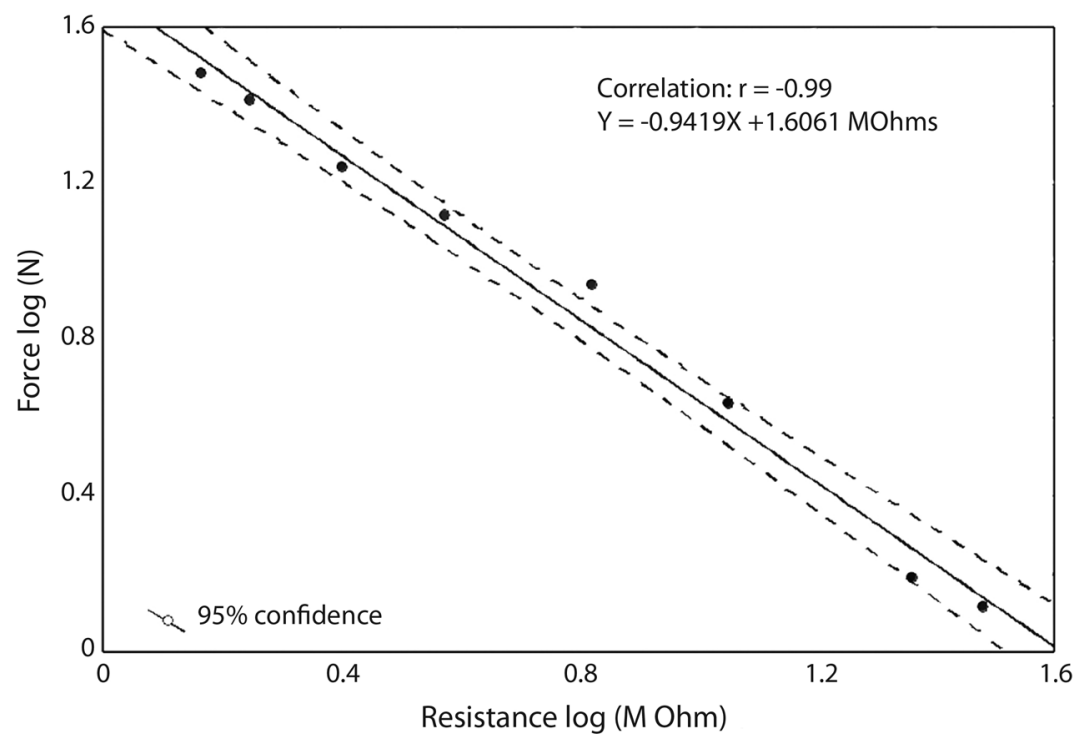

Fig. 2. Estimations of the bite force from the resistance measurements. Points correspond to known control weights of steel nuts $(\mathrm{N}=8)$ applied on the plate of the piezo resistive force sensor. The resistances recorded (M $\Omega)$ for Myotis vivesi were transformed to bite force values $(\mathrm{N})$ using this linear regression. 
differences between most pairs of species ( $\mathrm{P}<$ 0.001), except for the comparison between $M$. capaccinii and $M$. daubentonii, and with $M$. velifer $(\mathrm{P}>0.05)$.

The first CVA from sixteen variables (unadjusted for size) estimated five significant canonical vectors $(\mathrm{P}<0.0001)$ for 6 a pRiori groups. The first canonical function accounted for $86 \%$ of variance (Wilks' $\lambda<0.0001 ; \chi_{80}^{2}$ $=2508.21, \mathrm{P}<0.0001)$. The second canonical variable accounted for an additional $12 \%$ of the variance (Wilks' $\lambda=0.002 ; \chi_{60}^{2}=1340.53$, $\mathrm{p}<0.0001)$. The first two canonical axes indicate differences between species groups
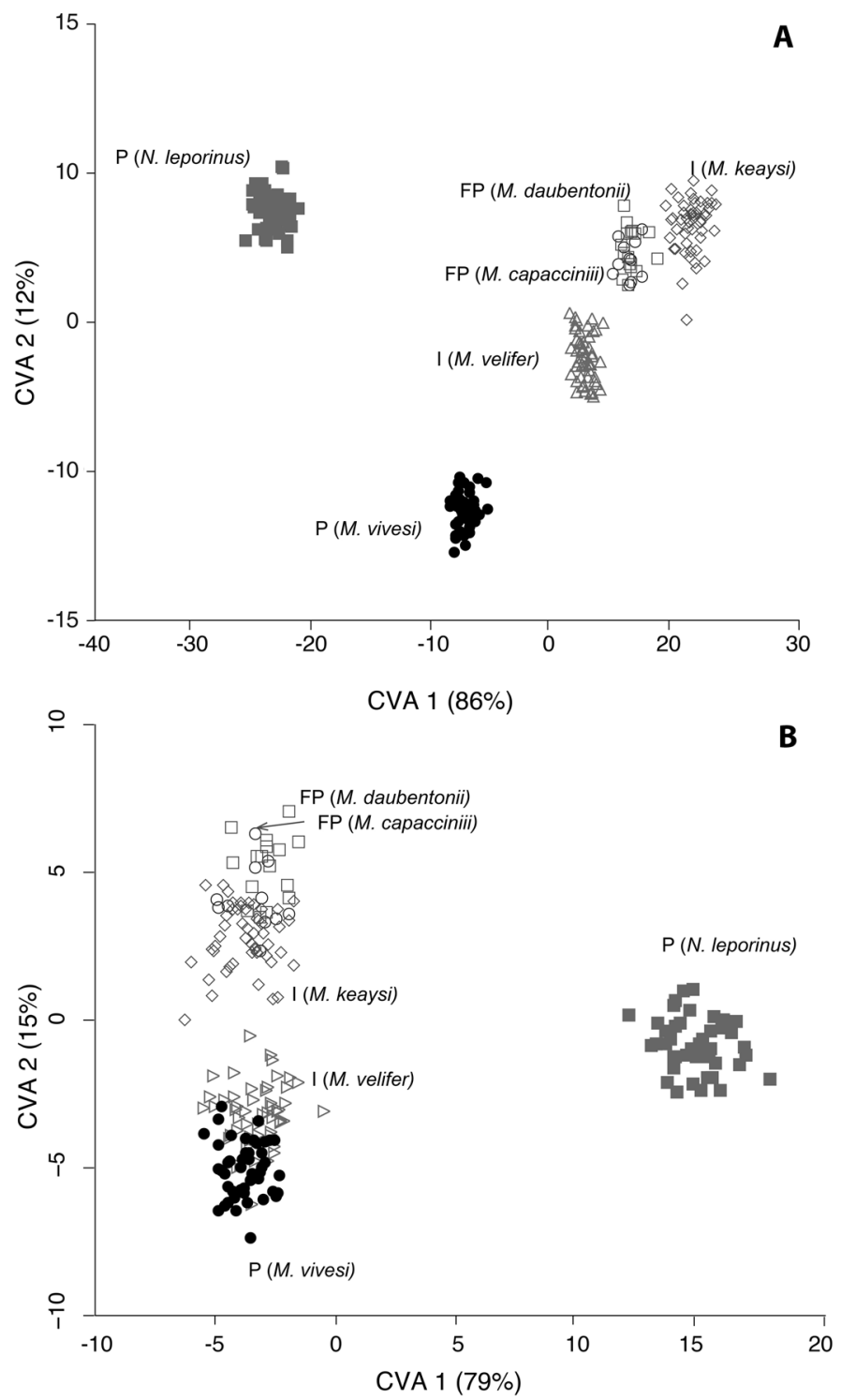

Fig. 3. Morphological variation of the masticatory apparatus in the fishing bat Myotis vivesi compared to insectivorous (I), facultatively piscivorous (FP), and piscivorous (P) bat species. A. Plot of first two significant axes of the CVA analysis from 14 measurements and two angles on skulls and jaws for six species $(\mathrm{N}=228)$. B. Plot of first two significant axes of the CVA analysis from 13 size corrected measurements (GLS excluded) and two angles on skulls and jaws for six species $(\mathrm{N}=228)$. 

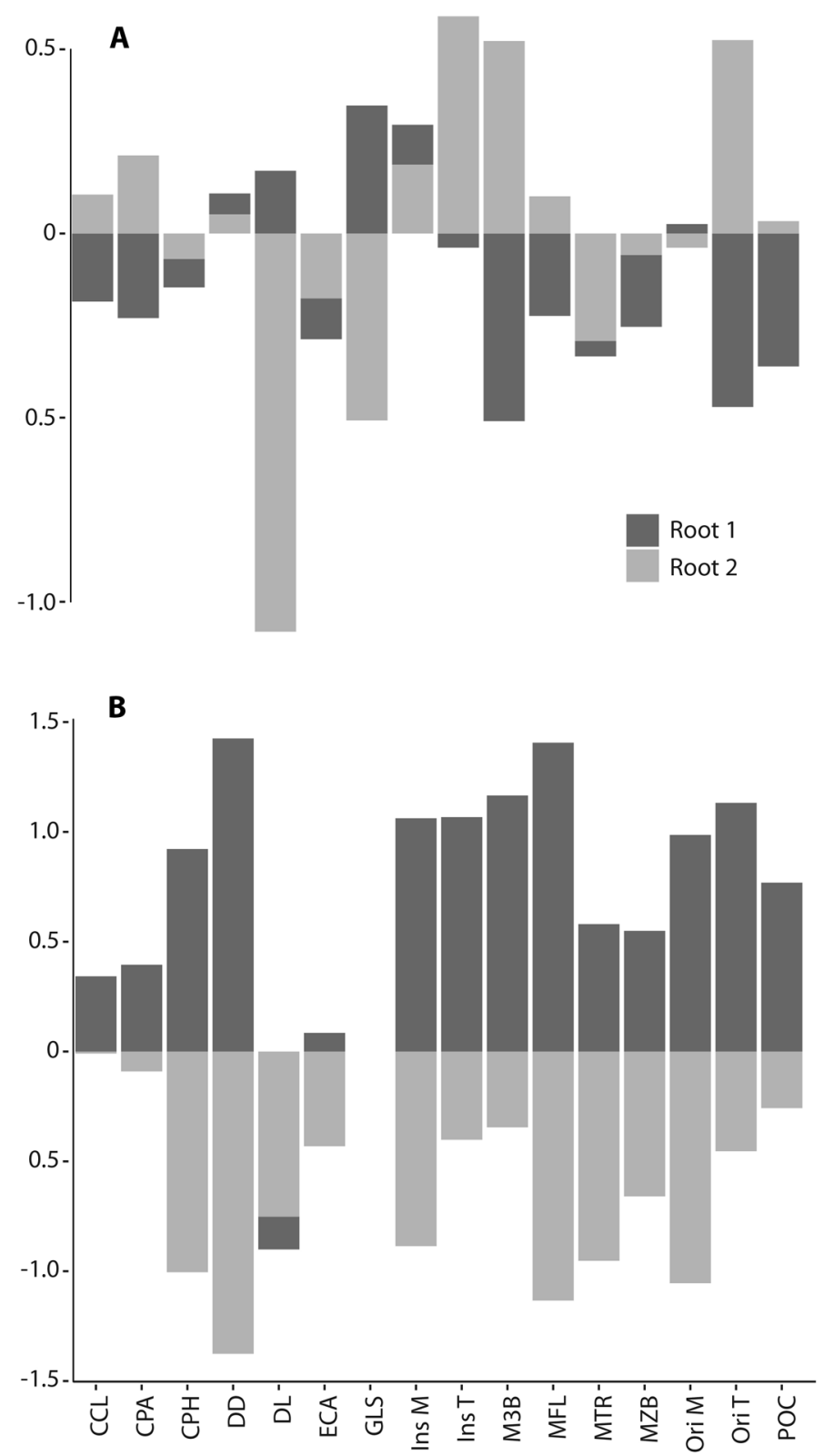

Fig. 4. Comparison of variable loadings from two CVA analyses of A. original and B. size corrected measurements.

(Fig. 3A). The contributions of variables to the first two canonical axes are presented in Fig. 4A. The species with insectivorous diets (M. keaysi and $M$. velifer) together with the facultatively piscivorous species (M. capaccinii and $M$ daubentonii) appeared on the righthand side on axis 1 , and the piscivorous species
$N$. leporinus is in the extreme left-hand side. Along the first canonical variate, $N$. leporinus had the most contrasting morphology of the six species examined. Therefore, the comparison of this species against all others forms the basis of the first discriminant function. The first two canonical variates revealed that the cranial 
morphology of $M$. vivesi was very different from the morphology of the two insectivorous and the two facultatively psicivorous species. Both canonical variables also reveal that the masticatory apparatus of $M$. vivesi was very different from $N$. leporinus. Variables that mostly contribute to the separation of both species were the cranial distances GLS, M3B, POC and Ori T, on the first canonical axis. The GLS, Ins T and DL had the highest contribution on the second canonical axis, discriminating $M$. vivesi from other Myotis species.

In the second CVA analysis (size corrected variables and GSL excluded), the ordination of species was different to the first CVA analysis, with Myotis species at the same position on CV1 and non-closely related Noctilio placed apart (Fig. 3B). This analysis determined five significant canonical vectors $(\mathrm{P}<0.0001)$ for 6 a pRiori groups. The first canonical function accounted for $79 \%$ of variance (Wilks' $\left.\lambda=0.00013 ; \chi_{75}^{2}=1939.26, \mathrm{P}<0.0001\right)$. The second canonical variable accounted for an additional $15 \%$ of the variance (Wilks' $\left.\lambda=0.0081 ; \chi_{56}^{2}=1041.31, \mathrm{P}<0.0001\right)$. The contributions of variables to the first canonical axes are presented in Fig. 4B. Abbreviations of 14 cranial measurements and two angles are ordered as in Fig. 1. The values on the scale are the correlation coefficients between each measurement and the first two Canonical axes from both analyses. As in the first CVA, the first two canonical axes adequately described differences between species groups but showed more overlapping among Myotis species along the first axis (Fig. 3B). This size adjusted CVA ordination also reveals that cranial morphology of $M$. vivesi differs from $N$. leporinus. The contribution of variables was more uniformly distributed, however the DD and the MFL had the highest contribution on the first canonical axis (Fig. 4B). On the second canonical axis, we observe contrasting shape differences among $M$. daubentonii and $M$. capaccini with $M$. vivesi also explained by differences in DD, MFL and the Ori M. The scores of the size-adjusted CV1 remain highly correlated to GLS $\left(\mathrm{R}=0.81, \mathrm{~F}_{1}\right.$, $\left.{ }_{226}=446.7, \mathrm{P}<0.001\right)$.
Bite force and diet: Values from the Blomberg's K test $(\mathrm{K}=0.324, \mathrm{P}=0.938)$ reveal there is no phylogenetic signal in the residuals of the linear regression between bite force and skull size (GSL). The original values of bite force and GLS were highly correlated among species with different diets $\left(\mathrm{R}=0.839, \mathrm{~F}_{1,11}=\right.$ 26.29, $\mathrm{P}<0.001$, Fig. 5). Bite force measured in $M$. vivesi $(10.37 \pm 5.39 \mathrm{~N})$ was positioned within the $95 \%$ confidence interval of the regression. Size-corrected bite force of $M$. vivesi $(0.48 \pm 0.25 \mathrm{~N} / \mathrm{mm}$ GSL) was lower than in $N$. leporinus $(0.68 \pm 0.26 \mathrm{~N} / \mathrm{mm}$ GSL $)$.

\section{DISCUSSION}

Our comparison of Myotis species separated insectivorous, facultatively piscivorous, and piscivorous bats based in original and sizeadjusted variables of their skull morphology. As expected, cranial morphology in $M$. vivesi diverged from its insectivorous ( $M$. keaysi and $M$. velifer) and facultatively piscivorous relatives (M. capaccinii and $M$. daubentonii). Differences in the two CVA analyses indicate significant contribution of skull size to the discrimination among species in the first CVA and more uniformly distributed variable loads in the second CVA, where similarities among Myotis species are most evident. There were also differences in the two CVA analyses in the pattern of variable correlations. The contributions to discrimination axes were more dispersed among variables in the second CVA than in the first CVA. In the analysis of variance from variables not adjusted for size, the measurements that contributed most to the discrimination of $M$. vivesi on the first two canonical axes were the greater length of the skull, the postorbital constriction, the maxillary breadth across M3, the origin of the masticatory muscles (Ori $\mathrm{T}$ and Ori $\mathrm{M}$ ), and the elevation of the condyle angle. Most of these traits describe the masticatory muscle position suggesting differences among bats with different diets in the performance of the masticatory muscle (Nogueira et al., 2005), as in the case of facultatively piscivorous and insectivorous 


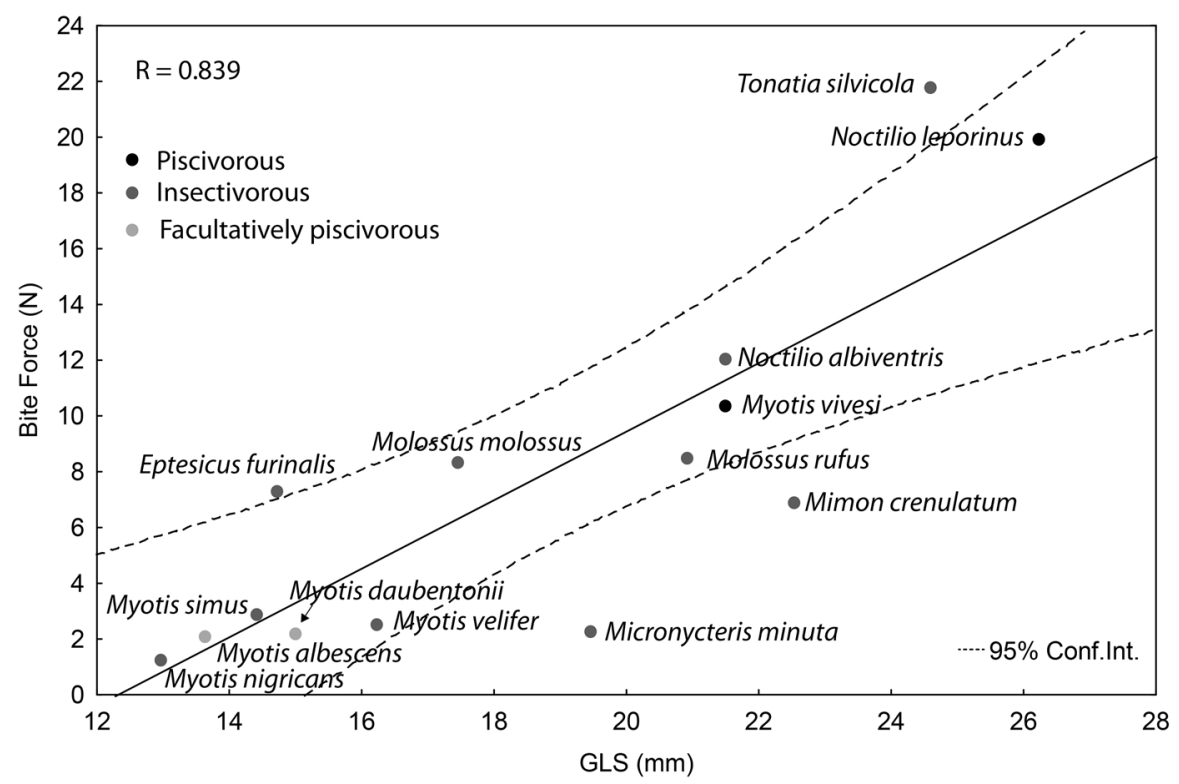

Fig. 5. Relationship between bite force and skull size (GSL) in bats with piscivorous and insectivorous feeding habits. Bite force for Myotis vivesi was well predicted by its GLS as it fell within the $95 \%$ confidence interval (dashed lines) of the regression.

Myotis. However, the ordination of species is congruent with size differences with largest species on the extreme of the first two canonical axes (N. leporinus in CV1 and M. vivesi in CV2) and the smallest species M. keaysi in the opposite direction.

The size adjusted CVA revealed different trends of variation. On the first axis, differences between the non-closely related piscivorous Noctilio and Myotis species were explained by the contribution of mandibular distances (DD and MFL), this could be related to the thickest mandible in Noctilio. On the second canonical axis, we observe contrasting shape differences between facultative piscivorous species $(M$. daubentonii and M. capaccinii) and M. vivesi, with $N$. leporinus in the middle of this axis, also explained by differences in mandibular distances (DD, MFL) and the origin of the masseter muscle. These trends in variation also hint to the different values of the origin/insertion ratio for the masseter muscle between $M$. vivesi (1.95) and the two facultative piscivorous species $(<1.79)$. Observed morphometric differences in the CVA adjusted for size support the idea that masseter muscle performance could be fundamental in diet differences inside Myotis (Ospina-Garcés et al., 2016).

Within Myotis, the two CVA ordinations suggest three different groups, each one including species with more similar morphometric distances and associated with three diets (Fig. 3 ). The length of the origin and insertion of the temporal muscle (OriT and InsT) were greater in $M$. vivesi than in insectivorous and facultatively piscivorous species. These two measurements reflect differences in the size and development of temporal muscle fibers (Nogueira et al., 2005). Larger temporal fibers are related to an increase in body size and bite force, due to a positive relationship with muscle mass (Herrel et al., 2008; Nogueira et al., 2005, 2009). Also, the elevation of condyle angle in $M$. vivesi $\left(52-62^{\circ}\right)$ indicates a functional change in the masticatory muscles position with respect to the insectivorous species $\left(43-53^{\circ}\right)$ and the facultatively piscivorous species $\left(46-53^{\circ}\right)$. These differences suggest a more 
vertically displaced orientation of the temporal muscle in $M$. vivesi than in other insectivorous and facultatively piscivorous species of Myotis.

Cranial morphotypes in $M$. vivesi and the non-related piscivorous $N$. leporinus were different in size and cannot be interpreted as parallelism. However a trend of increase size seems to be affecting morphological descriptors of masticatory muscles. In the first CVA analysis (Fig. 3A), the measurements that contributed most to the difference between $M$. vivesi and $N$. leporinus were the origin (Ori T) and the maxillary breadth across M3 (M3B). The length and height of the temporal muscle were smaller in $M$. vivesi than in $N$. leporinus (Table 1), but higher than in the other Myotis. These two variables had a size component and indicate the development of the masseter muscle in these piscivorous species being gradual to the insectivorous Myotis to piscivoros Myotis and Noctilio. Our results from the second CVA analysis with size-corrected variables and GLS excluded still suggest that most differences in cranial morphology between $M$. vivesi and $N$. leporinus are due to their differences in cranial proportions (Fig. 3B). In this analysis, the strong correlation between skull size (GLS) and the scores of the first CV indicate that size effect was reduced but not completely eliminated, as, it has been found for diverse methods to correct size effects on traditional morphometric variables (Adams, Rohlf, \& Slice, 2004).

Differences between the two piscivorous species can be further explained probably in function of phylogenetic distance, because they belong to unrelated families with different geographic origins (Jones et al., 2002), and this can be explored using additional characters and other methodological approaches to study shape and including lineages representing size variation between these two genera and families.

Skull size (GLS) and bite force were significantly related in bat species with different diets as previously reported (Aguirre et al., 2002). Bite force measured for $M$. vivesi fitted well the predictions for its size. Size-corrected bite force in $M$. vivesi was lower than that measured in $N$. leporinus, suggesting differences in the performance of the masticatory apparatus of these piscivores. Size-corrected bite force in $M$. vivesi ( $0.48 \mathrm{~N} / \mathrm{mm}$ GSL) was higher than in insectivorous and facultatively piscivorous Myotis (0.16-0.2 N/mm GSL; Aguirre et al., 2003), which suggests that piscivory in this genus required stronger bites. However, sizecorrected bite force appears to increase with size in bats (Fig. 5), and its value in M. vivesi is similar to that of unrelated insectivorous bats of similar size, such as $N$. albiventris $(0.55 \mathrm{~N} /$ mm GSL; Aguirre et al., 2003) and Molossus rufus (0.41 N/mm GSL; Aguirre et al. 2003). Therefore, the importance of bite force for the adoption of piscivorous habits in Myotis bats is unclear and warrants further tests that include congeners similar to $M$. vivesi size. However, the revealed differences in skull size, shape, and bite force among facultative piscivorous and piscivorous Myotis species can possibly be adaptations for prey on vaRious fish species.

Expected morphological similarities in gape due to parallelism in piscivorous species are not evident in $M$. vivesi and $N$. leporinus. A difference in the elevation condyle angle seems to have functional implications in the piscivorous diet. A high gape angle is possible when the position of the temporal muscle allows a higher moment around the temporo-mandibular joint (TMJ), as it has been shown in mammals with hard diets (Herring \& Herring, 1974; Reduker, 1983; Santana, Dumont, \& Davis, 2010). This pattern is documented in N. lepori$n u s$, which displays a vertical temporal muscle and a high gape angle related to the capture of prey on water surface (Freeman, 1988). Myotis vivesi had a lower elevation of the condyle angle than $N$. leporinus (64 to $74^{\circ}$ ). This angle indicates the orientation of the temporal muscle (Emerson \& Radinsky, 1980; Freeman, 1988; Van Cakenberghe et al., 2002; Dumont et al., 2009), and determines the action line of the force (Nogueira et al., 2005; Radinsky, 1982). A vertical orientation of the temporal muscle of $N$. leporinus is associated with a greater gape and lower effort required to process food (Freeman, 1988). The angles measured for $M$. 
vivesi were intermediate between $N$. leporinus and the group of insectivorous and facultatively piscivorous Myotis species. However, bite force might have a synergistic effect with the gape angle in $M$. vivesi. The orientation of the temporal muscle in $M$. vivesi is close to being vertical, which may explain its capacity to generate just enough bite force in function of its skull size to process fish but at a lower gape angle than $N$. leporinus.

Our morphometric analyses did not find cranial morphological similarities as expected between the piscivorous $M$. vivesi and $N$. leporinus. The two piscivorous species differed in size and particularly in the angles and proportions of the masticatory apparatus; this suggests that there is no parallelism associated to fisheating in the measured variables. Bite force in $M$. vivesi is explained by a moderate increase of skull size. $M$. vivesi had a more robust cranial morphology than its facultatively piscivorous and insectivorous congeners, but not as large as in N. leporinus. The increase in cranial size, the existence of a vertically displaced temporal muscle, and a greater gape angle that allows a moderate bite force, appear to be associated with the appearance of piscivory in $M$. vivesi.

Ethical statement: authors declare that they all agree with this publication and made significant contributions; that there is no conflict of interest of any kind; and that we followed all pertinent ethical and legal procedures and requirements. A signed document has been filed in the journal archives.

\section{ACKNOWLEDGMENTS}

This study was funded by a research grant from Dirección General de Asuntos del Personal Académico (DGAPA, UNAM), and sabbatical grants (CONACyT \#146770, DGAPA \#1404) to LGHM (\#IN201108). A graduate student fellowship by the Consejo Nacional de Ciencia y Tecnología (CONACyT, México) supported SMOG. Transportation to Partida Norte island was generously provided by Secretaría de Marina-Armada de México. The
Prescott College Kino Bay Center provided invaluable logistic support during fieldwork. Samples were collected with permission from the Secretaría de Medio Ambiente y Recursos Naturales and CONANP (México).

\section{RESUMEN}

Fuerza de mordida, morfología craneal y tamaño del murciélago pescador Myotis vivesi (Chiroptera: Vespertilionidae). La alimentación por peces en murciélagos evolucionó independientemente en Myotis vivesi (Vespertilionidae) y Noctilio leporinus (Phyllostomidae). En este estudio se compararon características craneales morfológicas y fuerza de mordida entre estas especies, para probar la existencia de paralelismo evolucionario en piscivoría. Se recolectaron distancias craneales en $M$. vivesi, dos parientes insectívoros ( $M$. velifer y $M$. keaysi), dos murciélagos piscívoros facultativos ( $M$. daubentonii y $M$. capaccinii), y $N$. leporinus. Se analizaron datos morfométricos aplicando múltiples métodos para probar las diferencias entre las seis especies. Se midió la fuerza de mordida en $M$. vivesi y se evalúo si puede ser predicha por el tamaño del cráneo. Las especies piscívoras fueron morfológicamente diferentes de las facultativamente piscívoras y las insectívoras, el tamaño del cráneo tuvo una contribución significativa en esta diferencia. Sin embargo, no encontramos semejanzas morfológicas y funcionales que puedan ser interpretadas como paralelismos entre $M$. vivesi y $N$. leporinus. Estas dos especies piscívoras difieren significativamente en medidas craneales y fuerza de mordida. La fuerza de mordida en $M$. vivesi fue efectivamente predicha por el tamaño de cráneo. La piscivoría en $M$. vivesi puede estar asociada con la existencia de un músculo temporal verticalmente desplazado y el incremento en el ángulo de apertura mandibular que permite moderar la fuerza de mordida para procesar el alimento.

Palabras clave: fuerza de mordida; morfología craneal; Myotis; Noctilio; piscivoría; tamaño; ángulo de apertura mandibular.

\section{REFERENCES}

Adams, D. C., Rohlf, F. J., \& Slice, D. E. (2004). Geometric morphometrics: ten years of progress following the 'revolution'. Italian Journal of Zoo$\log y, 71,5-16$.

Aguirre, L. F., Herrel, A., Van Damme, R., \& Matthysen, E. (2002). Ecomorphological analysis of trophic niche partitioning in a tropical savannah bat community. Proceeding of the Royal Society, 269, $1271-1278$ 
Aguirre, L. F., Herrel, A., Van Damme, R., \& Matthysen, E. A. (2003). The implications of food hardness for diet in bats. Functional Ecology, 17, 201-212.

Aihartza, J. R., Almenar, D., Goiti, U., Salsamendi, E., \& Garin, I. (2008). Fishing behavior in the longfingered bat Myotis capaccinii (Bonaparte, 1837), an experimental approach. Acta Chiropterologica, 10, 287-301.

Blood, B. R., \& Clark, M. K. (1998). Myotis vivesi. Mammalian Species, 588, 1-5.

Dumont, E. R. (1999). The effect of food hardness on feeding behavior in frugivorous bats (Phyllostomidae), an experimental study. Journal of Zoology, 248, 219-229.

Dumont, E. R., \& Herrel, A, (2003). The effects of gape angle and bite point on bite force in bats. The Journal of Experimental Biology, 206, 2117-2123.

Dumont, E. R., Herrel, A., Medellin, R. A., VargasContreras, J., \& Santana, A. (2009). Built to bite, cranial design and function in the wrinkle-faced bat. Journal of Zoology, 279, 329-337.

Emerson, S. B., \& Radinsky, A. (1980). Functional Analysis of Sabertooth Cranial Morphology. Paleobiology, 6, 295-312.

Findley, J. S. (1972). Phenetic Relationships among bats of the genus Myotis. Systematic Zoology, 21, 31-52.

Flannery, T. (1995). Mammals of the South-West Pacific \& Moluccan Islands. Chatswood, Australia: Australian Museum, Reed Books.

Freeman, P. W. (1981). Correspondence of food habits and morphology in insectivorous bats. Journal of Mammalogy, 62, 166-171.

Freeman, P. W. (1984). Functional cranial analysis of large animalivorous bats (Microchiroptera). Biological Journal of the Linnean Society, 21, 387-408.

Freeman, P. W. (1988). Frugivorous and Animalivorous bats (Microchiroptera) dental and cranial adaptations. Biological Journal of the Linnean Society, 33, 249-272.

Freeman, P. W., \& Lemen, C. A. (2008). Measuring bite force in small mammals with a piezo-resistive sensor. Journal of Mammalogy, 89, 513-517.

Freeman, P. W., \& Lemen, C. A. (2010). Simple predictors of bite force in bats: the good, the better and the better still. Journal of Zoology, 282, 284-290.

Ghazali, M., \& Dzeverin, I. (2013). Correlations between hardness of food and craniodental traits in nine Myotis species (Chiroptera, Vespertilionidae). Vestnik Zoologii, 47, 67-76.
Herrel, A., De Smet, A., Aguirre, L. F., \& Aerts, P. (2008). Morphological and mechanical determinants of bite force in bats, do muscles matter? The Journal of Experimental Biology, 211, 86-91.

Herring, S. W., \& Herring, S. E. (1974). The superficial masseter and gape in mammals. American Naturalist, 108, 561-576.

Jones, K. E., Purvis, A., Maclarnon, A. N. N., BinindaEmonds, O. R., \& Simmons, N. B. (2002). A phylogenetic supertree of the bats (Mammalia: Chiroptera). Biological Reviews, 77, 223-259.

Krüger, F., Clare, E. L., Greif, S., Siemers, B. M., Symondson, W. O. C., \& Sommer, R. S. (2014). An integrative approach to detect subtle trophic niche differentiation in the sympatric trawling bat species Myotis dasycneme and Myotis daubentonii. Molecular Ecology, 23, 3657-3671.

Law, N., \& Urquhart, C. A. (2000). Diet of the largefooted Myotis macropus at a forest stream roost in northern New South Wales. Australian Mammalogy, $22,121-124$.

Lewis-Oritt, N., Van Den Bussche, R. A., \& Baker, R. J. (2001). Molecular evidence for evolution of piscivory in Noctilio (Chiroptera, Noctilionidae). Journal of Mammalogy, 82, 748-759.

Nogueira, R. M., Monteiro, L., Peracchi, A. L., \& De Araújo, A. F. B. (2005). Ecomorphological analysis of the masticatory apparatus in the seed-eating bats, genus Chiroderma (Chiroptera, Phyllostomidae). Journal of Zoology, London, 266, 355-364.

Nogueira, R. M., Peracchi, A. L., \& Monteiro, L. (2009). Morphological correlates of bite force and diet in the skull and mandible of phyllostomid bats. Functional Ecology, 23, 715-713.

Norberg, U. M., \& Rayner, J. M. V. (1987). Ecological morphology and flight in bats (Mammalia; Chiroptera), wing adaptations, flight performance, foraging strategy and echolocation. Philosophical Transactions of the Royal Society, 316, 335-427.

Ospina-Garcés, S. M., De Luna, E. D., Herrera M., L. G., \& Flores-Martínez, J. J. (2016). Cranial shape and diet variation in Myotis species (Chiroptera, Vespertilionidae), testing the relationship between form and function. Acta Chiropterologica, $18,163-180$

Pacheco, V., \& Patterson, B. D. (1992). Systematics and biogeographic analyses of four species of Sturnira (Chiroptera, Phyllostomidae), with emphasis on Peruvian forms. Memorias del Museo de Historia Natural UNMSM, 21, 57-81.

R Core Team (2008). R program (version 3.3.3) [Computer program]. Retrieved from http://www.R-project.org. 
Reduker, D. W. (1983). Functional analysis of the masticatory apparatus in two species of Myotis. Journal of Mammalogy, 64, 277-286.

Revell, L. J. (2010). Phylogenetic signal and linear regression on species data. Methods in Ecology and Evolution, 1, 319-329.

Revell, L. J. (2012). Phytools: an R package for phylogenetic comparative biology (and other things). Methods in Ecology and Evolution, 3, 217-223.

Rohlf, J. (2005). TpsDIG2 (version 2) [Computer program]. Retrieved from http://life.bio.sunysb.edu/ morph

Ruedi, M., \& Mayer, F. (2001). Molecular systematics of bats of the genus Myotis (Vespertilionidae) suggests deterministic ecomorphological convergences. Molecular Phylogenetics and Evolution, 21, 436-448.

Santana, S. E., Dumont, E., \& Davis, J. J. (2010). Mechanics of bite force production and its relationship to diet in bats. Functional Ecology, 24, 776-784.

Siemers, B. M., Dietz, C., Nill, D., \& Schnitzler, H. U. (2001). Myotis daubentonii is able to catch small fish. Acta Chiropterologica, 3, 71-75.

Sikes, R. S., \& Gannon, W. L. (2011). The Animal Care and Use Committee of the American Society of
Mammalogists, Guidelines of the American Society of Mammalogists for the use of wild mammals in research. Journal of Mammalogy, 92, 235-253.

Stadelmann, B., Herrera, L. G., Arroyo-Cabrales, J., Flores-Martinez, J. J., May, B. P., \& Ruedi, M. (2004). Molecular systematics of the fishing bat Myotis (pizonyx) vivesi. Journal of Mammalogy, 85, 133-139.

StatSoft Inc. (2011). Statistica (Version 10) [Computer program]. Tulsa, Oklahoma: StatSoft Inc.

Swartz, S. M., Freeman, P., \& Stockwell, E. F. (2003). Ecomorphology of bats, Comparative and experimental approaches relating structural design to ecology. In T. H. Kunz, \& B. Fenton (Eds.), Bat Ecology (pp. 257-300). Chicago: The University of Chicago Press.

Van Cakenberghe, V., Herrel, A., \& Aguirre, L. F. (2002). Evolutionary relationships between cranial shape and diet in bats (Mammalia,Chiroptera). In P. Aerts, K. D'Août, A. Herrel, \& R. Van Damme (Eds.), Topics in Functional and Ecological Vertebrate Morphology (pp. 205-236). Maastricht: Shaker Publishing.

Whitaker, J., \& Findley, J. S. (1980). Foods eaten by some bats from Costa Rica and Panama. Journal of Mammalogy, 61, 540-544. 


\section{APPENDIX \\ Specimens examined. Specimen catalog numbers are listed according to country and locality or province}

Museum acronyms are as follows: $\mathbf{C N M = ~ N a t i o n a l ~ M a m m a l ~ C o l l e c t i o n , ~ U n i v e r s i d a d ~ N a c i o n a l ~}$ Autónoma de México (México). EBD= the Doñana Biological Station, Sevilla (Spain). INAH= Osteological Collection, Instituto Nacional de Antropología e Historia (México). IPN= Mammal collection, Instituto Politécnico Nacional, México. $\mathbf{Z M B}=$ Humboldt University Natural History Museum, Berlin (Germany).

M. capaccinii- EBD: Taforalt, Morocco: 15528, 15533, 15594, 15615. ZMB: 67025, 67023, 67022, 85321, 15002, 85322, 4049.

M. daubentonii- ZMB: Braunschweig, Germany: 577, 44053, 44050, 67563, 59320, 55170, 55511, 55168. Rostock, Germany: 70805, 70811, 92492, 85854, 85862, 92495, 92494, 93583.

M. keaysi- CNM: Tabasco, México: 6804, 7723, 7724, 7727, 7876, 7877, 7878. Yucatán, México: 16345, 18510, 18951, 19278, 19279, 19283, 20268, 20938, 20939, 20940, 20942, 20944, 20946, 20947, 20948, 20949, 22726, 24472, 28872, 28868, 28869, 32853, 32854, 32855, 32857, 32858, 34756, 36660, 43536. INAH: 5382, 5206 IPN: 18685, 18697, 18696, 18694, 18869, 18695, 18693, 18691, 18688, 18692, 24194, 18686.

M. velifer- CNM: Morelos, México: 5157, 5158, 5161, 5159, 5167, 7156, 7902, 7903, 8241, 9069, 9450, 9761. Coahuila, México: 13820 13567.Baja California, México: 15571, 15572. Puebla, México: 16867,18605, 18607, 18609, 18610. Durango, México: 19684, 19685, 19687, 19750, 19996, 19999, 20000, 20001, 28855, 28856, 28857, 28858, 28859, 28860, 28861. INAH: 5700, 5701, 5702. IPN: 7414, 7415, 7417, 2151, 2155, 2157, 2156, 2159, 2160, 2161, 2162, 2164, 2165, 2168.

M. vivesi- CNM: Isla Partida Norte, México: 2193, 7716, 15658, 15660, 15661, 15662 , 15663, 15664, 15659, 16803, 16805, 16806, 16807, 23909, 23910, 23912, 23913, 23914, 23915, 30327, 39327, 45675, 45676, 45677, 45679, 45680, 45681, 45682, 41683, 45684, 45685, 45686, 45689, 45690, 45691, 45693, 45696, 45697. IPN: 38764, 38765, 5168, 5183, 5184, 38766, 38767, $38768,38769$.

N. leporinus- CNM: Tonalá, Chiapas, México: 5921, 6208, 6209, 6210, 6211, 6212, 6213, $6214,6215,6216,6217,6218,6219,6220,6221,6222,6490,6623,6931$. Rio popoyuta, Michoacán, México: 17133, 17135, 18118, 19117, 19116, 19119, 19120. Guerrero, México: 34400, 34401, 23701, 27886, 34402, 34403. 